Kohl: a Journal for Body and Gender Research

Vol. 6, No. 1 (Summer 2020)

\title{
Tensions as a Way of Being
}

Ghiwa Sayegh 
It is in tension that I come to this editorial. I realized, too late, that I should have asked another team member to open our (now twelfth) issue on Tensions in Movement Building. I had already shifted our publication schedule by twenty-four hours to accommodate for my tardiness, and I woke up exhausted after yet another night of poor sleep. It felt like "productivity" was the least productive thing to pursue. And yet, I pushed myself beyond what felt possible, because of deadlines, because of responsibility, because of accountability to all those who have worked so hard and waited so patiently for this issue to see the light.

I am mentioning this because these are the workings of tensions. Often, tensions are described in punitive terms; they are portrayed as conflicts where all parties are equally guilty of wrongdoing. What we fail to see, however, is how trauma and power are at the core of the tensions we experience at face value. Tensions are difficult; they are messy; they demand courage and perseverance and healing; sometimes they are intransigent, and other times, they call for forgiveness. And thus, to embrace tensions as a way of being, as accountability, is to look at (the misuse of) power in the eye and to make space for the complexities that might come with that acknowledgement.

When we published the call for this issue, our hope was to document, following a "clean," sanitized methodology of archiving, the tense politics that communities thought to be part of the same "movement" experience, embody, and live. This was an oversight. We had failed to take into account the mess of affect, of heartbreaks, of rage, of vulnerability, of sheer resistance, of solidarity and kinship. Thankfully, the authors of this issue have remedied to that, doing this issue justice. They have also taught me - alongside my therapist and loved ones - how to make space for emotions and their chaos as a political act.

I would like to take a moment to reflect on the editorial exchange we had with Samaa Elturkey, who wrote an article titled "Is it Rape or a 'Disgraceful Act?' Transformative Justice as an Alternative Approach of Addressing Sexual Violence in Egypt's Civil Spaces" for this issue. After a round of edits, we had a call with Samaa, where we engaged in debating the nuances and detailed motions of wording: what would this adjective convey? Could that qualification be misinterpreted as endorsement? Would that other formulation silence or cancel those who have been vocal? This is the emotional labor that tensions require of us. Words matter, especially when we are not heard, when we withdraw from processes, or when we are not afforded speech. After we finalized the piece, Samaa informed me that she added a concluding paragraph that documents her own writing process, as an individual who is not divorced from Egypt's scene and whose traumas and triggers were activated during said process.

Transformative justice is especially about how entire communities can radically address violence as structural without canceling each other, by going beyond individual and isolated blame. Those who are willingly putting themselves out there, exposing their own vulnerabilities, are calling on us to engage in this community work of care. To honor their labor, I invite us all to consider transformative justice as a methodology from below. My aim here is not to eradicate tensions, but to recognize that it is the insidious, unrecognized, and hidden power dynamics to which they are entangled that make them so toxic. It is a call to deal in tensions so we are eventually collectively transformed. 
This issue was supposed to be out in December 2019. It is six months late against the backdrop of revolutions, economic collapse, and a pandemic. These manifests of a trilogy of oppression (mass surveillance, capitalism, and necropolitics) also remind us of how power operates - by rejecting all forms of accountability, by controlling and manipulating information for mass consumption, by canceling those we think will never rise up again. Necropolitics are pervasive. And loss and mourning, no matter how devastating, are our resistance against erasure - that we might face death, physical or psychological, and still rise because, as Audre Lorde reminds us, "we were never meant to survive." Along the way, we lost Sarah Hegazy; we lost too many to racist violence, to failing, defunded healthcare systems, to occupation and apartheid, to capitalistic greed and profit, to industrial complexes, to mass repression and silencing. And we especially lost ourselves and each other.

In this litany of loss (rather than survival), I think of Roula, who just left Kohl. Roula Seghaier joined Kohl as managing editor at the beginning of 2016, and together we founded Intersectional Knowledge Publishers the following year. Roula taught me that integrity and solidarity are an ongoing, uncomfortable practice. So many times, we leaned on each other to survive. And I believe that this is exactly what we did when we decided to go our separate paths, so that these might cross again. Sometimes, we leave as survival; we let each other go so that a "we" might survive.

I come to tensions full circle, still bolstered by Roula's legacy. I might not know how to ask of people to be compassionate while they hurt, rage, and mourn - and that is okay. Housekeeping (in community terms) is contingent on our mental health, our ability to absorb and process continuous violence, and the many crises we navigate and attempt to get through. Therefore, we might falter, mess up, get triggered, lash out, react in panic and fear - and that is also okay. My hope is that despite it all, we may always find community support so that our collective commitment to processes and justice are upheld, so that we can dismantle the systems - all the systems - that oppress us, and hold those at the top who deliberately sustain and profit off of them accountable. On my Instagram stories today, Sadie Lune posted: "Fight will open some doors, but ongoing sustainable care work is the home of the revolution." Revolutions "at home" - in our movements, communities, and kinship structures - are personal as much as they are transnational, and compassion from within tensions is our most intimate transformation towards radical justice. 